\title{
Effects of Manganese Complexes of Curcumin and Diacetylcurcumin on Kainic Acid-Induced Neurotoxic Responses in the Rat Hippocampus
}

\author{
Yaowared Sumanont,${ }^{a}$ Yukihisa Murakami, ${ }^{a}$ Michihisa Tohda,,${ }^{a}$ Opa VajRagupta, ${ }^{c}$ \\ Hiroshi Watanabe, ${ }^{d}$ and Kinzo Matsumoto*,a,b \\ ${ }^{a}$ Division of Medicinal Pharmacology, Institute of Natural Medicine, University of Toyama; ${ }^{b} 21$ st COE Program, \\ University of Toyama; 2630 Sugitani, Toyama 930-0194, Japan: ${ }^{c}$ Department of Pharmaceutical Chemistry, Faculty of \\ Pharmacy, Mahidol University; Bangkok 10400, Thailand: and ${ }^{d}$ International Research Center for Traditional Medicine, \\ Toyama Prefecture International Health Complex; Toyama 939-8224, Japan.
}

Received March 23, 2007; accepted June 19, 2007; published online June 22, 2007

This study aimed to investigate the mechanism underlying the protective effects of manganese complexes of curcumin (Cp-Mn) and diacetylcurcumin (DiAc-Cp-Mn) on kainic acid (KA)-induced excitotoxicity in the rat hippocampus. Systemic injection of KA $(10 \mathrm{mg} / \mathrm{kg}$, i.p.) caused seizures and increased the expression of neurotoxic markers, immediate early genes [c-jun, cyclooxygenase 2 (COX-2), brain-derived neurotrophic factor (BDNF), and heat shock protein 70 (hsp 70)] and a delayed response gene [inducible nitric oxide synthase (iNOS)], which were measured at 6 and $72 \mathrm{~h}$ after KA injection, respectively, in the hippocampus. Pretreatment with Cp-Mn (50 mg/kg, i.p.) and DiAc-Cp-Mn (50 mg/kg, i.p.) but not with curcumin $(50 \mathrm{mg} / \mathrm{kg}$, i.p.) delayed the onset of KA-induced seizure without affecting the seizure score. KA injection induced c-Fos immunoreactivity in DG, CA1, and CA3 hippocampal regions, the expression of which peaked at $6 \mathrm{~h}$ after injection. Cp-Mn and DiAc-Cp-Mn treatment significantly decreased c-Fos expression elicited by KA. Moreover, Cp-Mn and DiAc-Cp-Mn administration suppressed the KA-induced expression of c-jun, COX-2, BDNF, and iNOS mRNA, whereas curcumin attenuated only $i N O S$ mRNA expression. No compounds tested had an effect on KA-induced hsp70 expression. It is therefore likely that in addition to radical scavenging and SOD-like activities, the suppression of potential neuronal injury marker expression by $\mathrm{Cp}-\mathrm{Mn}$ and $\mathrm{DiAc}-\mathrm{Cp}-\mathrm{Mn}$, contributes to the neuroprotective activities of these compounds, which are superior to those of curcumin, on KA-induced excitotoxicity in the hippocampus. These results suggest the beneficial effects of $\mathrm{Cp}-\mathrm{Mn}$, and DiAc-Cp-Mn on the treatment of excitotoxicity-induced neurodegenerative diseases.

Key words curcumin manganese complex; kainic acid-induced excitotoxicity; seizure; immediate early gene

Lines of evidence indicate that curcumin (diferuloylmethane), a major constituent of a medicinal plant rhizome Curcuma longa, has a wide range of beneficial pharmacological effects including antiinflammatory, antioxidant, anti-carcinogenic, and antiviral effects. It acts as an antioxidant by scavenging various free radicals such as peroxyl, hydroxyl and nitrogen dioxide radicals; however, a recent study has demonstrated that curcumin is not an effective scavenger for superoxide radical $\left(\mathrm{O}_{2}^{-}\right)$and a large concentration of curcumin is required for trapping this radical species. ${ }^{1)}$

We have previously synthesized manganese $(\mathrm{Mn})$ complexes of curcumin and diacetylcurcumin $(\mathrm{Cp}-\mathrm{Mn}$ and DiAc- $-\mathrm{Cp}-\mathrm{Mn}$ ) and reported that $\mathrm{Cp}-\mathrm{Mn}$ and $\mathrm{DiAc}-\mathrm{Cp}-\mathrm{Mn}$ (Fig. 1-I) exert more potent SOD-like activity than curcumin and diacetylcurcumin, respectively. Moreover, these complexes had hydroxyl radical ${ }^{2)}$ and nitric oxide (NO)-scavenging activities, ${ }^{3)}$ inhibited lipid peroxidation and $\mathrm{H}_{2} \mathrm{O}_{2}$-induced neuronal cell damage in in vitro, and showed preventive effects on transient cerebral ischemia-induced learning and memory deficits, an in vivo neurodegenerative model which involves oxidative stress in the brain. ${ }^{4}$

Of particular relevance to neuronal excitotoxicity, kainic acid (KA), an analog of the excitatory amino acid L-glutamate, has been used to provide a reliable model of excessive activation of glutamate receptor. KA depolarizes neurons via activating kainate-type glutamate receptors located on, and thereby results in severe status epilepticus, overproduction of NO, and selective neuronal cell death, in the rat hippocampus. ${ }^{5,6)}$ In our previous study, $\mathrm{Cp}-\mathrm{Mn}$ and DiAc-Cp-
Mn attenuated the KA-induced increase in NO level in the hippocampus and prevented KA-induced neuronal cell loss in CA1 and CA3 subfields of the hippocampus ${ }^{3}$; however, the exact molecular and cellular mechanisms responsible for the neuroprotective effects of these compounds remain unclear.

Excessive production of radical species plays an important role in neuronal pathology resulting from excitotoxic insults $^{7-9)}$; therefore, one plausible neuroprotective mechanism of $\mathrm{Cp}-\mathrm{Mn}$ and DiAc-Cp-Mn is partly relevant to their antioxidative properties. However, various mechanisms have been proposed to account for the pathological manifestations observed after systemic administration of KA. For example, KA induces excitotoxic damage by triggering seizure followed by hypoxia and edema. Evidence suggests that acute neuronal cell degeneration elicited by KA contributes to KAinduced seizure severity ${ }^{10)}$ In addition, the activation of intracellular signaling cascades induced by excitotoxins leads to short-term and long-term changes in gene expression in the brain. There are two sets of distinguished genes: immediate-early genes (IEGs) such as proto-oncogenes of c-fos and c-jun families, cyclooxygenase-2 (COX-2), brain-derived neurotrophic factor (BDNF), and heat shock protein gene families which are activated rapidly and transiently. Their mRNA levels peak at $4-6 \mathrm{~h}$ following KA administration, while delayed-response genes or target genes of the former group are activated in the late phase of the neuronal cell death process. ${ }^{11)}$

Proto-oncogenes of fos and jun families encode proteins 
Fos and Jun, respectively. Fos-Jun heterodimers are major components of the transcription factor activator protein 1 (AP-1) ${ }^{12)}$ In the brain, transcriptional factors of the Fos and Jun families have been implicated in cell proliferation, gene transcription, stress responses, regeneration, and cell death. ${ }^{13)}$ Indeed, c-Fos and c-Jun have been presented as markers of neuronal cell death following KA injection. ${ }^{14)}$ On the other hand, systemic administration of KA causes inflammatory and stress response in the brain, leading to the induction of COX-2, iNOS and heat shock protein (HSP70). ${ }^{11)}$ These genes are considered to be leading factors contributing to delayed neuronal cell death. ${ }^{11,13)}$ Additionally, BDNF, a neurotrophic factor of the neurotrophin family, has been suggested to play a particularly important role in the brain. Experimental manipulations that induce seizures cause a dramatic elevation of $B D N F$ mRNA level in widespread brain areas including the hippocampus. ${ }^{15,16)}$ Based on these findings, the expression of BDNF has been suggested to occur as a trophic response to neuronal injury. ${ }^{17}$ )

The above findings prompted us to investigate the molecular mechanism underlying the protective effects of $\mathrm{Cp}-\mathrm{Mn}$ and DiAc-Cp-Mn on KA-induced neuronal cell death. In this study we examined the effects of these compounds on $\mathrm{KA}$-induced seizure and elevation of the expression of c-Fos protein, c-jun, $C O X-2, B D N F$ and $h s p 70$ and iNOS genes which serve as indices of neurotoxicity. Immunohistochemical studies were also performed to determine the time course of the expression and cellular localization of c-Fos protein in the hippocampus region.

\section{MATERIALS AND METHODS}

Materials Curcumin, curcumin manganese complex $(\mathrm{Cp}-\mathrm{Mn})$ and diacetylcurcumin manganese complex (DiAc$\mathrm{Cp}-\mathrm{Mn}$ ) were prepared as described previously. ${ }^{4}$ Kainic acid and sodium carboxymethyl cellulose (CMC) were purchased from Tocris (Ellis, MO, U.S.A.) and Nacalai Tesque (Kyoto, Japan), respectively. Specific amplification primers for each gene of interest were designed on the basis of DNA sequences and supplied from Wako Pure Chem. (Osaka, Japan).

Animals A total of 56 male Wistar rats (9-10 weeks old; Japan SLC Inc., Shizuoka, Japan) weighing 280-330 g were used in this study. All animals were housed in a temperature-controlled room $\left(25 \pm 1{ }^{\circ} \mathrm{C}\right)$ with $65 \pm 5 \%$ humidity and $12 \mathrm{~h}$ light-dark cycle (lights on: 07:30 - 19:30) and had free access to food and water. All experimental procedures were performed in accordance with the standards established by the Guide for the Care and Use of Laboratory Animals of the University of Toyama.

Drug Administration KA $(10 \mathrm{mg} / \mathrm{kg})$ was dissolved in $0.9 \%$ saline and the test compounds, curcumin, $\mathrm{Cp}-\mathrm{Mn}$, and DiAc-Cp-Mn, were dispersed in 5\% carboxymethyl cellulose (CMC). These drugs were administered intraperitoneally (i.p.) in a constant volume of $1 \mathrm{ml} / \mathrm{kg}$. According to our previous report, ${ }^{18)}$ the animals were pretreated with the test compounds $(50 \mathrm{mg} / \mathrm{kg}$, i.p.) or corresponding vehicles 40 min before KA injection.

Behavioral Study The dose of the convulsant, KA, 10 $\mathrm{mg} / \mathrm{kg}$, was the same as in the previous study. ${ }^{18)}$ After KA injection, animals were placed individually in a plastic cage and behavioral activities were continuously monitored for 3 h. Latency to the first appearance of clearly defined 'wet dog shakes' after KA injection was recorded as the seizure latency. The behavioral seizures induced by KA were scored according to the rating scale of Sperk et al., ${ }^{5)}$ as follows: 0, normal behavior; 1, 'wet dog shakes'; 2, strongly increased rate of 'wet dog shakes', mild myoclonic twitching of head, face and/or forelimbs; 3, intermittent seizures affecting the whole body and foaming at the mouth; 4, prolonged, generalized severe seizures with frequent rearing and falling over to one side; 5, generalized seizures with early death. Each animal was assigned the score of the most severe seizure observed.

Immunohistochemistry For immunohistochemical assessment, the time course of KA-induced c-Fos protein expression was determined at time points ranging from 3 to $72 \mathrm{~h}$ after KA injection. The effect of the test compounds on $\mathrm{KA}$-induced c-Fos protein expression was examined at $6 \mathrm{~h}$ after KA injection. The animals were decapitated under pentobarbital $(50 \mathrm{mg} / \mathrm{kg}$, i.p.) anaesthesia. The brains were removed immediately, frozen in dry-ice powder, and kept at $-80{ }^{\circ} \mathrm{C}$ until processed for immunohistochemistry. Coronal sections of the brain ( $10 \mu \mathrm{m}$ thick) were prepared using a cryostat (CM3000, Leica) and every fifth section was thawmounted onto gelatinized slides. Frozen sections were fixed with $4 \%$ paraformaldehyde for $10 \mathrm{~min}$, followed by washing with phosphate buffer solution (PBS, $\mathrm{pH}$ 7.4). Endogenous peroxidase was quenched with methanol solution containing $0.3 \% \mathrm{H}_{2} \mathrm{O}_{2}$ for $30 \mathrm{~min}$ and then washed out three times with PBS for $5 \mathrm{~min}$ each. Sections were incubated for $1 \mathrm{~h}$ in PBS containing 5\% goat serum and $0.6 \%$ Triton $\mathrm{X}-100$, and then excess serum was blotted from the sections, which were incubated overnight at $4{ }^{\circ} \mathrm{C}$ with the selective antibody directed against c-Fos (sc-52, Santa Cruz Biotechnology, Santa Cruz, CA, U.S.A.). The dilution of c-Fos was $1: 1000$ in $0.6 \%$ Triton $\mathrm{X}-100$ in PBS with $2 \%$ normal goat serum. The sections were then washed three times with PBS for $5 \mathrm{~min}$ each and incubated with the secondary antibody (1:500, biotinylated anti-IgG antibody, Vector Laboratories) $1 \mathrm{~h}$ at room temperature, washed three times for $5 \mathrm{~min}$ in PBS, processed with avidin-biotinylated horseradish peroxidase complex $(1: 250$ in PBS, Vectastain Elite ABC kit, Vector Laboratories) for $1 \mathrm{~h}$, and washed three times for $5 \mathrm{~min}$ with PBS. Subsequent antibody visualization was carried out using 3,3'-diaminobenzidine (DAB kit; Vector Laboratories) as the chromogen for $10 \mathrm{~min}$ in buffer containing nickel chloride. The sections were washed three times with PBS, air-dried, dehydrated in graded ethanol solutions, cleared in xylene, and embedded in Entellan (Merck, Darmstadt, Germany). Immunohistochemical controls received the same reaction procedures in the absence of the primary antibody.

Quantitative Analysis of c-Fos Immunohistochemistry Photomicrographs of brain sections were taken using an inverted microscope (Olympus PROVIS AX80 $0^{\circledR}$, Tokyo, Japan) equipped with a digital camera (Olympus DP50). The densities of c-Fos-stained nuclei appearing as grey-black stains were counted in regions CA1, CA3, and dentate gyrus of the dorsal hippocampus with ImageJ software as previously described. ${ }^{19)}$ Briefly, the densities of nuclei with c-Fos immunoreactivity were counted as the number of immunostained nuclei within the analyzed region, divided by the area 
of that region (measured on the picture and expressed in pixels). Arbitrary units of density (a.u.) were defined as the number of nuclei divided by the area in pixels. The number of stained nuclei was automatically counted with the 'Threshold' function of the ImageJ program, which marks all the pixels of the chosen grey value and counts all the groups of marked pixels (stained nuclei) within the area of 0.0225 $\mathrm{mm}^{2}$ in hippocampal CA1, CA3, and DG subfields.

Real-Time Polymerase Chain Reaction (Real-Time PCR) The effects on KA-induced expression of immediate early genes $40 \mathrm{~min}$ after pretreatment with the test compounds were determined. The c-jun, $C O X-2, B D N F$ and hsp 70 mRNAs were assayed at $6 \mathrm{~h}$ after KA administration as in previous reports. ${ }^{11,20)}$ The time course of KA-induced $i N O S$ gene expression was prior elucidated, and then the induction of $i N O S$ mRNA was determined at $72 \mathrm{~h}$ after KA injection. The rats were decapitated and their brains were dissected out on ice. Total RNA was extracted from the hippocampi using Sepazol ${ }^{\circledR}$ (Nacalai Tesque, Kyoto, Japan) according to the manufacturer's instructions. First-strand cDNA synthesis from total RNA $(2 \mu \mathrm{g})$ was conducted using $0.5 \mu \mathrm{M}$ oligo(dT) primer and 200 units of reverse transcriptase $(\mathrm{Su}-$ perscript II ${ }^{\circledR}$, Invitrogen, Rockville, MD, U.S.A.) at $42{ }^{\circ} \mathrm{C}$ for $60 \mathrm{~min}$ and terminated at $70^{\circ} \mathrm{C}$ for $15 \mathrm{~min}$.

Quantitative real-time RT-PCR was carried out using realtime SYBR ${ }^{\circledR}$ Premix EX Taq (Takara, Shiga, Japan) in a Smart Cycler ${ }^{\circledR}$ II System (Cepheid) according to the manufacturer's instructions. The primers and product size of each gene were as follows: c-jun (232 bp); 5'-AAC GGT CTC ACG TCA GTG TA-3' (forward) and 5'-TCT GGC TAT GCA GTT CAG CTA G-3' (reverse), COX-2 (374 bp); 5' AGT GAT CGA AGA CTA CGT GC-3' (forward) and 5'TGC GGT ACT CAT TGA GAG AC-3' (reverse), BDNF (222 bp); 5'-ACA GTA TTA GCG AGT GGG TCA C-3' (forward) and 5'-GAA CAT ACG ATT GGG TAG TTC G-3' (reverse), $h s p 70$ (251 bp); 5'-CCT GGA GAT CGA CTC TCT GTT-3' (forward) and 5'-GAT TGA TGC TCT TGT TCA GGT C-3' (reverse). For amplification of the iNOS gene, two sets of primers were used for nested PCR as follows: 1st PCR (511 bp); 5'-CCA AGA GTT TGA CCA GAG GA-3' (forward) and 5'-TCG ATG CAC AAC TGG GTG AA-3' (reverse), 2nd PCR (216 bp); 5'-AAC AGG AAC CTA CCA GCT CA-3' (forward) and 5'-AAC ACA GTA ATG GCC GAC CT-3' (reverse). Primers for $\beta$-actin, a housekeeping gene, were as follows: 5'-AAC GGT CTC ACG TCA GTG TA-3' (forward) 5'-GTG ACA GCA TTG CTT CTG TG-3' (reverse) and its product size was $222 \mathrm{bp}$. Cycling parameters for $\beta$-actin and nested PCR of iNOS mRNA were: $15 \mathrm{~s}$ at $94^{\circ} \mathrm{C}$ followed by 45 cycles of $10 \mathrm{~s}$ at 94 ${ }^{\circ} \mathrm{C}, 15 \mathrm{~s}$ at $57^{\circ} \mathrm{C}$ and $10 \mathrm{~s}$ at $72^{\circ} \mathrm{C}$. Cycling parameters for $\mathrm{c}$ jun, $C O X-2, B D N F$ and $h s p 70$ were: $10 \mathrm{~s}$ at $94^{\circ} \mathrm{C}$ followed by 45 cycles of $5 \mathrm{~s}$ at $94^{\circ} \mathrm{C}$ and $20 \mathrm{~s}$ at $62^{\circ} \mathrm{C}$. Melting curve analysis of each gene was performed every time after finishing amplification. Since it is difficult to determine the absolute amount of cDNA present in different samples, the quantitation of test mRNA transcripts is generally normalized to a reference gene such as $\beta$-actin gene, presumed to be invariant. The change in the expression of target genes, c-jun, $C O X-2, B D N F, h s p 70$, and $i N O S$ relative to $\beta$-actin, was quantified according to the Smart Cycler ${ }^{\circledR}$ System (Takara). Standard curves of the $\log$ concentration of each gene $v s$. cycle threshold were plotted to prove reverse linear correlations. The correlation coefficients for standard curves of target genes were 0.9465 to 0.9904 .

Statistical Analysis The seizure severity score recorded in the behavioral study was analyzed by Kruskal-Wallis analysis of variance on rank followed by Dunn's test for comparison with a KA-treated control group $(n=11-13)$. Other data were analyzed by one-way ANOVA followed by the Student Newman-Keuls test for multiple comparisons among different groups. The data were expressed as the mean \pm S.E.M. Differences of $p<0.05$ were considered significant.

\section{RESULTS}

Effects of Cp-Mn and DiAc-Cp-Mn on KA-Induced Seizures Systemic administration of KA produced wellcharacterized complex seizure activity. The rats exhibited immobility, rigid postures, and staring as initial responses after $\mathrm{KA}$ injection. After $30-40 \mathrm{~min}$, these behaviors were replaced by 'wet dog shakes', 'head nodding', and subsequent mouth automatisms, salivation, and falling. Eventually, the rats developed status epilepticus lasting for more than $3 \mathrm{~h}$. The latency to the first "wet dog shake" was $36.5 \pm 2.4 \mathrm{~min}$ in rats treated with KA alone, while pre-treatment with $\mathrm{Cp}-\mathrm{Mn}$ and DiAc- $\mathrm{Cp}-\mathrm{Mn}$ but not with curcumin significantly elongated the latency of the first "wet dog shake" (Fig. 1-IIA). However, neither the Mn complexes nor curcumin lowered the mean seizure score of the KA-treated animals significantly (Fig. 1-IIB).

Effect of Curcumin, Cp-Mn and DiAc-Cp-Mn on KAInduced c-Fos Protein Expression Figure 2 indicates the temporal features of c-Fos protein expression in the rat hippocampus after KA-induced seizures. In vehicle-treated rats, c-Fos immunoreactivity was observed slightly in a few neurons of the hippocampus, while apparent anti-c-Fos immunostaining was firstly observed in the DG at $3 \mathrm{~h}$ after KA injection (Fig. 2). c-Fos expression peaked at $6 \mathrm{~h}$ post-KA injection and was distributed strongly in the CA1, CA3, hilus of DG, and DG areas (Fig. 2). The c-Fos immunoreactivity in these regions was observed until $24 \mathrm{~h}$ after KA treatment. On the basis of these results, the effects of curcumin, $\mathrm{Cp}-\mathrm{Mn}$, and DiAc- $\mathrm{Cp}-\mathrm{Mn}$ were examined at $6 \mathrm{~h}$ after KA injection. As shown in Fig. 3, administration of Cp-Mn and DiAc-CpMn prior to KA significantly decreased anti-c-Fos immunostaining in all regions of CA1, CA3, and DG, whereas curcumin partially inhibited c-Fos expression only in the CA3 area.

Effects of Curcumin, Cp-Mn, and DiAc-Cp-Mn on the Expression of Immediate Early Genes Induced by KA To examine the effects of curcumin, $\mathrm{Cp}-\mathrm{Mn}$ and DiAc- $\mathrm{Cp}-\mathrm{Mn}$ on the KA-induced expression of immediate early genes, total RNA was isolated from the rat hippocampus at $6 \mathrm{~h}$ after KA injection and gene expressions were analyzed by real-time PCR. As shown in Fig. 4, KA injection significantly increased the expression levels of c-jun, COX-2, $B D N F$, and $h s p 70$ mRNA by approximately 3-, 4-, $2.5-$, and 2.3-fold over vehicle-control treatment, respectively. Pretreatment with $\mathrm{Cp}-\mathrm{Mn}$ and DiAc-Cp-Mn significantly suppressed the c-jun, $C O X-2, B D N F$ mRNA expressions induced by KA but had no effect on $h s p 70$ mRNA expression. In contrast, curcumin showed no inhibitory effect on KA-induced 
l)<smiles>COc1cc(/C=C/C(=O)/C=C/C(O)(Cl)Cl)ccc1O</smiles><smiles>COc1cc(/C=C/C2=C/C(=C\c3ccc(O)c(OC)c3)O[V]([O])(OC)O2)ccc1O</smiles><smiles>COc1cc(/C=C/C2=CC(/C=C/c3ccc(OC(C)=O)c(OC)c3)=NP3(=C(/C=C/c4ccc(OC(C)=O)c(OC)c4)C=C(/C=C/c4ccc(OC(C)=O)c(OC(C)=O)c4)O3)O2)ccc1O</smiles>

II)

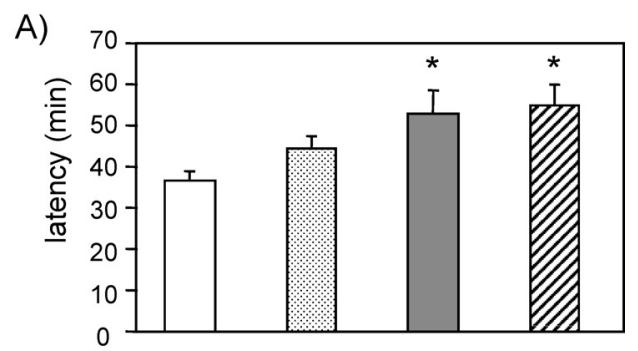

B)

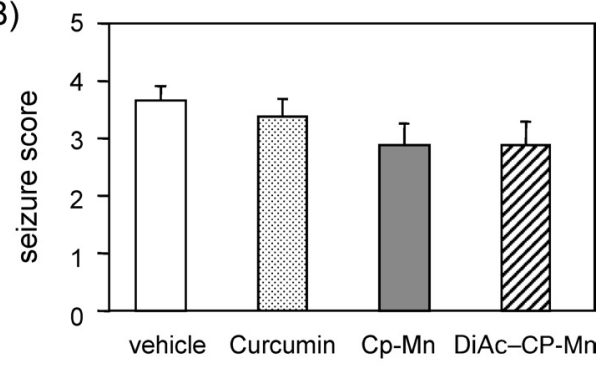

Fig. 1. Effects of Curcumin, $\mathrm{Cp}-\mathrm{Mn}$ and DiAc-Cp-Mn on Seizures Induced by KA

(I) The chemical structures of curcumin and curcumin manganese complexes ( $\mathrm{Cp}-\mathrm{Mn}$ and DiAc-Cp-Mn). (II) (A) The mean time from the injection of KA to the first wet dog shakes (latency). (B) Behavioral changes were observed for $3 \mathrm{~h}$ after injection of KA and the onset time of seizure was recorded as the latency (min) and the severity of seizure appeared in each animal was scored according to the criteria described in the text. Each column represents the mean \pm S.E.M., indicated $(n=11-13)$. The data were analyzed by Kruskal-Wallis analysis of variance on rank followed by Dunn's test for comparison with a KA-treated control group. Note that pretreatment with Cp-Mn and DiAc-Cp-Mn but not with curcumin delayed the onset of seizure without affecting the severity of seizures. $* p<0.05 v s$. KA-treated group.

\section{A. Control}

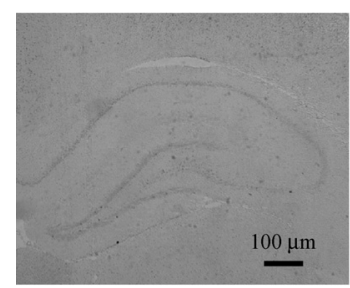

\section{KA, $24 \mathrm{~h}$}

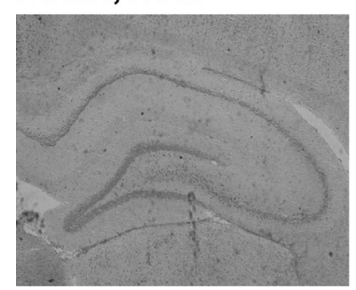

B. KA, $3 \mathrm{~h}$

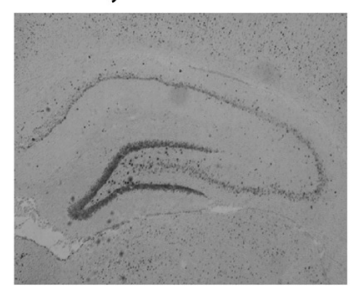

E. KA, $48 \mathrm{~h}$

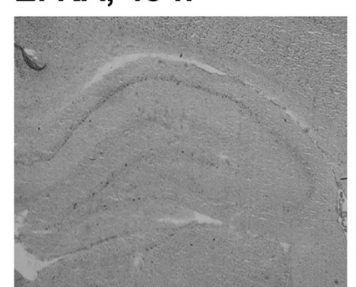

\section{C. $\mathrm{KA}, 6 \mathrm{~h}$}

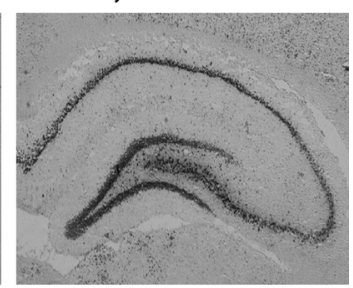

\section{F. KA, 72 h}

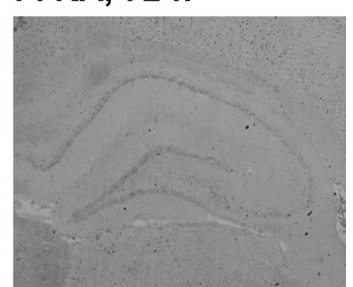

Fig. 2. Micrographic Analysis of the Time Course of c-Fos Protein Expression in the Rat Hippocampus after KA Injection

Hippocampal slices were prepared from rats which were decapitated at 3 (B), 6 (C), 24 (D), 48 (E), and 72 (F) h after KA (10 mg/kg, i.p.) injection. The hippocampal sections prepared from control rats revealed very slight c-Fos immunoreactivity in pyramidal neurons and in DG. c-Fos immunoreactivity was initially observed at $3 \mathrm{~h}$ (B) in the DG area and peaked at $6 \mathrm{~h}$ throughout all regions of the hippocampus $(\mathrm{C})$. The inductions of c-Fos protein gradually decreased and returned to the basal control level within $48-72 \mathrm{~h}(\mathrm{D}, \mathrm{E}$, F). Scale bar, $100 \mu \mathrm{m}$

increase in the expressions of these mRNAs.

Effects of Curcumin, Cp-Mn, and DiAc-Cp-Mn on iNOS mRNA Expression Induced by KA In vehicletreated rats, iNOS mRNA expression was found to be low and poorly detected by nested PCR. KA injection did not change the expression level of $i N O S$ mRNA until $48 \mathrm{~h}$ after injection but markedly enhanced it at $72 \mathrm{~h}$ after injection (Fig. 5A). The effects of curcumin, $\mathrm{Cp}-\mathrm{Mn}$, and DiAc-Cp$\mathrm{Mn}$ on $i N O S$ mRNA expression at $72 \mathrm{~h}$ after KA injection were analyzed by a combination of nested PCR and real-time PCR. The results showed that KA caused a 1.8-fold increase in $i N O S$ mRNA expression compared to the control group, and that pretreatment with curcumin, $\mathrm{Cp}-\mathrm{Mn}$ and DiAc$\mathrm{Cp}-\mathrm{Mn}$ significantly decreased the $i N O S$ mRNA expression (Fig. 5B). 
A)

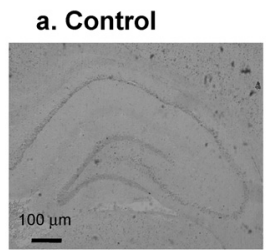

b. KA

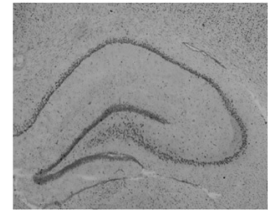

c. $\mathrm{KA}+$ curcumin

d. $K A+C p-M n$

e. $K A+D i A c-M n$
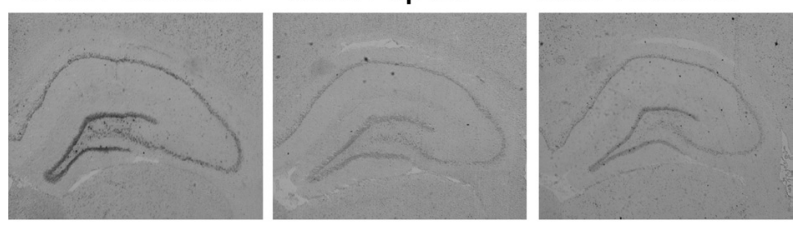

B)

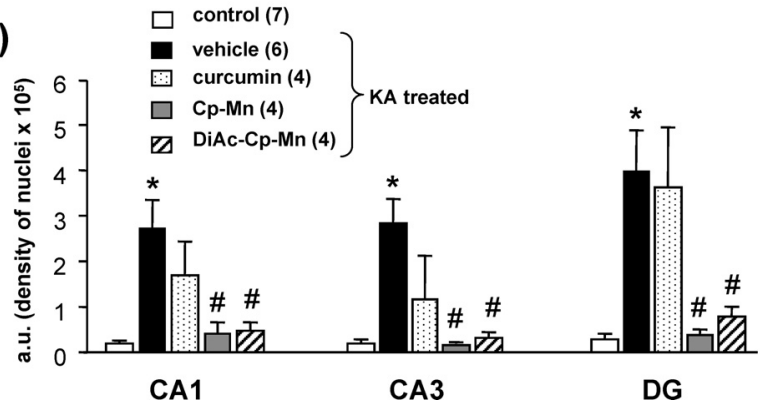

Fig. 3. Effects of Curcumin, Cp-Mn, and DiAc-Cp-Mn on the Hippocampal c-Fos Expression Induced by KA

(A) The photomicrographs are representative c-Fos immunostaining in the hippocampal sections from control and KA-treated rats with and without the test compounds, curcumin, $\mathrm{Cp}-\mathrm{Mn}$, and DiAc- $\mathrm{Cp}-\mathrm{Mn}$. The test compounds $(50 \mathrm{mg} / \mathrm{kg})$ or corresponding vehicle was given $40 \mathrm{~min}$ before KA injection. The animals were decapitated at $6 \mathrm{~h}$ after KA injection and hippocampal sections were prepared for c-Fos immunostaining. Scale bar, $100 \mu \mathrm{m}$. (B) Quantitative temporal analysis of c-Fos immunoreactivity in hippocampal cell regions in rats following KA injection. KA significantly induced c-Fos protein expression in CA1, CA3, and DG areas. Pretreatment with $\mathrm{Cp}-\mathrm{Mn}$ and DiAc-Cp-Mn completely reduced c-Fos immunoreactivity in all regions, whereas curcumin partially inhibited the expression of c-Fos protein only in the CA3 subfield as compare to KA-treated rats. The number of animals used in each group wa indicated in parentheses. Data represent the mean \pm S.E.M. $(n=4-7)$. ${ }^{*} p<0.05 v$ s. KAtreated group; $* p<0.01 v s$. saline group.
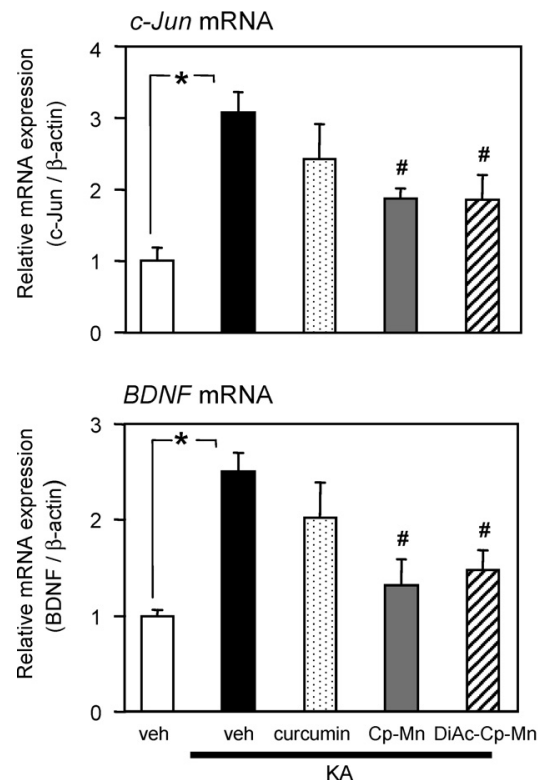

\section{DISCUSSION}

The major findings of this study are that systemic administration of $\mathrm{Cp}-\mathrm{Mn}$ and $\mathrm{DiAc}-\mathrm{Cp}-\mathrm{Mn}$ delayed the onset of

A)

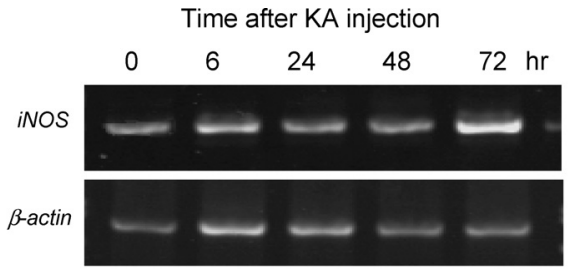

B)

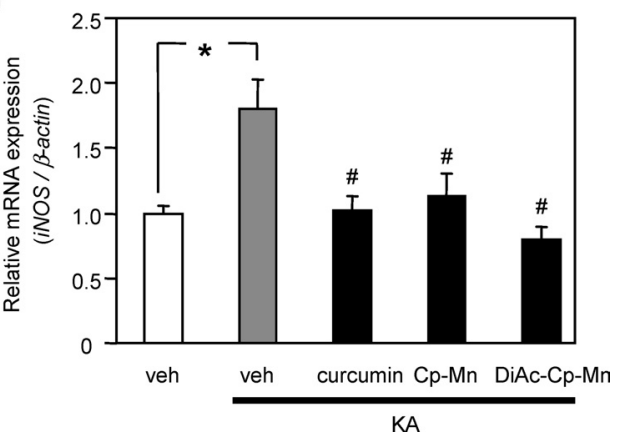

Fig. 5. Effect of Curcumin, Cp-Mn and DiAc-Cp-Mn on KA-Induced $i N O S$ Expression in the Hippocampus

(A) The time course of $i N O S$ and $\beta$-actin expression was caused by KA injection. Total RNA was prepared from the hippocampi of rats sacrificed at $0,6,24,48$, and $72 \mathrm{~h}$ after KA injection. cDNA was synthesized using Superscript $\mathrm{II}^{\circledR}$ enzyme (Invitrogen). RT-PCR of $i N O S$ mRNA was carried out using a nested PCR technique. (B) In drugtreated groups, rats were given the test drugs, curcumin, $\mathrm{Cp}-\mathrm{Mn}$ and $\mathrm{DiAc}-\mathrm{Cp}-\mathrm{Mn}$, at a dose of $50 \mathrm{mg} / \mathrm{kg}$ (i.p.) $40 \mathrm{~min}$ before receiving KA $(10 \mathrm{mg} / \mathrm{kg}$, i.p.). Seventy-two hours after KA injection, the brain was removed and the hippocampus region was dissected, followed by extracting the total RNA. cDNA was synthesized using Superscript $\mathrm{II}^{\circledR}$ enzyme (Invitrogen). iNOS mRNA expression was quantified with $\mathrm{SYBR}^{\circledR}$ Premix Ex Taq ${ }^{\mathrm{TM}}$ using the Smart Cycler $^{\mathbb{R}}$ II System. The mRNA levels of $i N O S$ were normalized to $\beta$-actin mRNA expression and are shown relative to the level in the control (vehicle-treated rat). Each column represents the mean \pm S.E.M. $(n=5-7) . * p<0.05 v s$. control group and $\# p<0.05 v s$. KA-treated group.
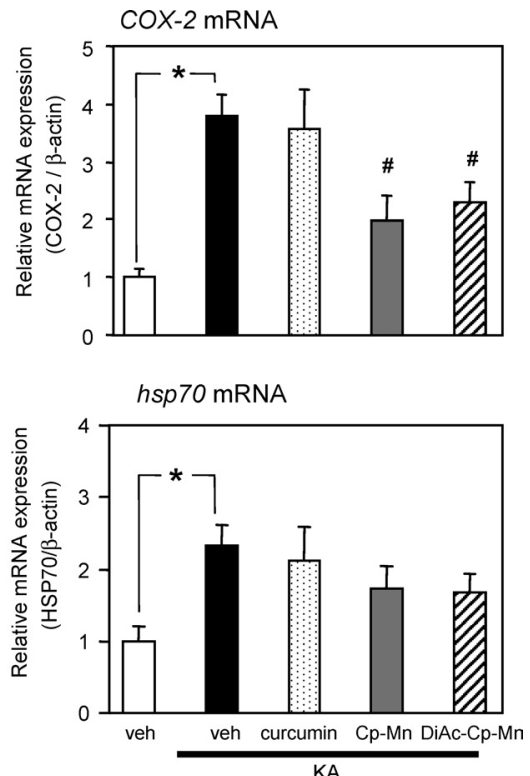

Fig. 4. Expression Profile of Immediate Early Genes (IEGs) Induced by KA with and without Pretreatment of Curcumin, Cp-Mn and DiAc-Cp-Mn

In drug-treated groups, rats were given the drug at a dose of $50 \mathrm{mg} / \mathrm{kg}$, i.p. $40 \mathrm{~min}$ before receiving $\mathrm{KA}(10 \mathrm{mg} / \mathrm{kg}$, i.p.). Six hours after injection of KA the brain was removed and the hippocampus was dissected, followed by extraction of total RNA. Total RNA was reverse-transcribed by Superscript II ${ }^{\circledR}$ enzyme (Invitrogen) to synthesize cDNA. The expressions of c-jun, COX-2, BDNF and hsp70 mRNA were identified with SYBR $^{\circledR}$ Premix Ex Taq ${ }^{\text {TM }}$ using Smart Cycler ${ }^{\circledR}$ II System. The mRNA levels of these IEGs were normalized to $\beta$-actin mRNA expression and were shown relative to the level in the control (vehicle-treated rat). Each column represents the mean \pm S.E.M. ( $n=5-7) . * p<0.05 v s$. control group and $\# p<0.05 v s$. KA-treated group. 
KA-induced seizure and reduced the expressions of c-Fos immunoreactivity, c-jun mRNA, $C O X-2$ mRNA, $B D N F$ mRNA and iNOS mRNA, while curcumin failed to affect KA-induced seizure and attenuated only iNOS mRNA expression. These findings suggested that $\mathrm{Cp}-\mathrm{Mn}$ and DiAc$\mathrm{Cp}-\mathrm{Mn}$ are useful neuroprotective agents in the treatment of brain pathologies associated with excitotoxicity such as epilepsy, stroke, ischemia, and traumatic brain injury.

Consistent with previous reports, ${ }^{5,6,21)}$ systemic administration of KA $(10 \mathrm{mg} / \mathrm{kg})$ produced well-characterized seizure in rats; i.e., staring, and immobility, which are attributable to selective activation of the hippocampus during the first stage of limbic seizures, subsequent 'wet dog shake' (a limbic seizure) behavior which is defined as seizure onset, automatisms and mild limbic convulsion, and then severe limbic convulsions due to extra-limbic system activation. ${ }^{22}$ Thus, KA induces seizures with a typical and gradual onset compared to other convulsant drugs. This study demonstrated that pretreatment with $\mathrm{Cp}-\mathrm{Mn}$ and DiAc-Cp-Mn delayed the onset of KA-induced seizures without affecting seizure severity. KA-induced 'wet dog shake' behavior reportedly represents neuronal hyperactivity in limbic structures that spread to midbrain areas and the motor system. ${ }^{22,23}$ ) Although the exact mechanism by which Mn complexes delayed the onset of 'wet dog shake' behavior remains unclear, our findings raise the possibility that $\mathrm{Cp}-\mathrm{Mn}$ and DiAc$\mathrm{Cp}-\mathrm{Mn}$ may have anticonvulsant-like properties.

Seizures have been shown to stimulate the expression of a variety of genes. $B D N F$ is a marker gene, the expression of which dramatically increases in areas of the limbic system, especially in the dentate gyrus (DG), and CA1 and CA3 pyramidal cell layers of the hippocampus. Interestingly, recent studies have shown that BDNF plays a pro-epileptic role by potentiating excitatory synapses through TrkB receptors. ${ }^{24}$ ) Moreover, BDNF reportedly causes hyper-excitability in both the normal and epileptic hippocampus ${ }^{16)}$ and over-expression of BDNF leads to increased seizure severity. ${ }^{25)}$ In contrast, reduced BDNF signaling delays the development of kindling. ${ }^{26,27)}$ The present study demonstrated that KA induced the expression of $B D N F$ mRNA in the hippocampus and that pretreatment with $\mathrm{Cp}-\mathrm{Mn}$ and $\mathrm{DiAc}-\mathrm{Cp}-\mathrm{Mn}$ attenuated the KA-induced elevation of $B D N F$ mRNA expression. This result suggests that the mechanism underlying the delay of seizure onset by $\mathrm{Cp}-\mathrm{Mn}$ and $\mathrm{DiAc}-\mathrm{Cp}-\mathrm{Mn}$ is at least involved in their suppression of $B D N F$ mRNA expression.

It has been reported that heat shock proteins (HSPs) are induced by an increase in body temperature and metabolic cell stress during seizures. In previous studies, HSP70 expression in the hippocampus positively correlated with the severity of KA-elicited limbic seizures and neuronal injury ${ }^{28,29)}$ and a decrease of limbic seizure severity attenuated the neuronal expression of HSP70. ${ }^{29)}$ In the present study, marked expression of $h s p 70 \mathrm{mRNA}$ in the hippocampus was observed at $6 \mathrm{~h}$ after KA injection, and pretreatment with curcumin, $\mathrm{Cp}-\mathrm{Mn}$ and DiAc-Cp-Mn failed to affect either the intensity of seizures or mRNA expression of $h s p 70$; therefore, it could be speculated that unaltered expression of HSP mRNA in KA-treated rats after $\mathrm{Cp}-\mathrm{Mn}$ and DiAc- $\mathrm{Cp}-$ Mn treatment may be relevant to the failure of these compounds to suppress seizure severities.

We observed the up-regulation of c-jun mRNA and c-Fos protein expression in DG, CA1, and CA3 regions of the hippocampus at $6 \mathrm{~h}$ after KA injection. These findings are consistent with previous studies demonstrating that KA induces the expression of c-Fos and c-Jun, components of the transcription factor AP-1 and that the expression of c-Fos and cJun participates in neuronal cell death. ${ }^{13,30)}$ Evidence indicates that binding of AP-1, homo or heterodimers which consist of family member proteins including c-Fos and c-Jun, to DNA, is increased by KA treatment in a biphasic manner: i.e., the first phase $(2-6 \mathrm{~h})$ being associated with seizures and the second ( $48-72 \mathrm{~h}$ ) corresponding to the period of delayed neuronal cell death. ${ }^{12,14}$ In a previous study, ${ }^{18)}$ severe neuronal cell loss in CA1 and CA3 but not DG subfields of the hippocampus was observed at $72 \mathrm{~h}$ after KA injection. Together, the present results indicate that the up-regulation of c-jun mRNA and c-Fos protein preceded neuronal cell loss in CA1 and CA 3 areas, and suggest that Fos and Jun proteins serve as the third messengers in the hippocampus which mediate the consequent events of neuronal cell death following KA administration. Moreover, it should be noted that pretreatment with $\mathrm{Cp}-\mathrm{Mn}$ and $\mathrm{DiAc}-\mathrm{Cp}-\mathrm{Mn}$ but not curcumin attenuated the KA-induced expression of c-jun mRNA and cFos immunoreactivity. Previously, we found that $\mathrm{Cp}-\mathrm{Mn}$ and DiAc- $-\mathrm{Cp}-\mathrm{Mn}$ increase the number of survival neuronal cells in KA-treated animals more than curcumin. ${ }^{18)}$ Together, the present results lead to the suggestion that $\mathrm{Cp}-\mathrm{Mn}-$ and DiAc-Cp-Mn-induced protection against KA-induced neuronal cell death may be due to their ability to decrease the expression of both c-jun mRNA and c-Fos protein.

Although c-Fos-immunoreactive neurons were widely distributed throughout CA1, CA3, and DG regions of the hippocampus after KA treatment, neuronal cell death was not induced in the DG subfield in this study. At least three possibilities seem to account for this discrepancy. First, factors other than c-Fos and c-Jun may increase the susceptibility of CA1 and CA3 pyramidal neurons to KA-induced neuronal toxicity. Indeed, there is a report ${ }^{31)}$ that mRNA expression of the apoptosis-related enzyme caspase 3 is substantially upregulated at $8 \mathrm{~h}$ post-KA in CA1 and CA3. Second, genes expressed solely in DG neurons may reduce the susceptibility of DG neurons to KA-induced neurotoxicity. Neuroprotective factors such as the protein inhibitor of nNOS and c-Jun $\mathrm{N}$-terminal kinase-interacting protein reportedly act as inhibitors of the apoptotic signaling pathway and these factors markedly increased in $\mathrm{DG}$ at $8 \mathrm{~h}$ following KA treatment. ${ }^{31)}$ Third, the difference in susceptibility to KA neurotoxicity among subfields of the hippocampus may depend on differences in the distribution of glutamate receptor subtypes in hippocampus subregions. Indeed, high-affinity KA receptors are preferentially located in the mossy fiber synaptic region of the CA3 region, while NMDA receptors are highly expressed in CA1 regions. ${ }^{5)}$

The present results revealed a marked expression of hippocampal $C O X-2 \mathrm{mRNA}$ at $6 \mathrm{~h}$ after KA injection. In particular, KA activates the glutamate $/ \mathrm{Ca}^{2+}$ cascade in neuronal cells and produces a marked increase in the level of intracellular $\mathrm{Ca}^{2+}$, leading to consequent over-activation of $\mathrm{Ca}^{2+}$-dependent enzymes such as phospholipase $\mathrm{A}_{2}$, which releases arachidonic acid, a substrate for COX-2. The early induction of COX-2 may fuel tissue damage through prostanoids and free radicals, while delayed neuronal cell death caused by 
KA may be associated with inflammatory response and apoptosis processes involving $\mathrm{COX}-2{ }^{32)}$ Inhibition of this enzyme attenuates the increase in prostaglandin $\mathrm{E}_{2}$, a major COX-2 product, and improves neuronal survival in the hippocampus of rats with KA-induced seizures. ${ }^{33)}$ Considering these findings, the mechanism underlying the prevention of KA-induced neuronal cell death by $\mathrm{Cp}-\mathrm{Mn}$ and $\mathrm{DiAc}-\mathrm{Cp}-\mathrm{Mn}^{18}$ ) may involve both suppressive effects on $C O X-2$ mRNA expression and antioxidant activity. In addition, since AP-1 is one of the factors responsible for the regulation of $C O X-2$ expression, ${ }^{34)}$ it is very likely that $\mathrm{Cp}-\mathrm{Mn}$ and $\mathrm{DiAc}-\mathrm{Cp}-\mathrm{Mn}$ decreased the expression of c-Fos protein and c-jun mRNA, and thereby inhibited $C O X-2$ mRNA expression.

In this study, we observed the enhanced expression of iNOS mRNA in the hippocampus at $72 \mathrm{~h}$ after KA injection. It is known that the induction of $i N O S$ mRNA expression is elicited by glial cell activation (microglia and astrocytes) and plays an important role in the delayed inflammatory process. Together with the previous findings that hippocampal tissues have already exhibited neuronal cell damage at $72 \mathrm{~h}$ after KA treatment, ${ }^{18}$ the present results suggest that NO production via iNOS induction seems poorly related to KA-induced neuronal cell damage.

The present result revealed that curcumin, $\mathrm{Cp}-\mathrm{Mn}$, and DiAc-Cp-Mn almost completely suppressed the KA-induced increase in $i N O S$ mRNA expression. The mechanisms underlying the effects of these compounds on $i N O S$ gene expression are not well understood. Lines of evidence, however, indicate that the regulation of $i N O S$ mRNA expression depends on the formation of a multiple intracellular signaling complex composed of Janus kinases, protein tyrosine kinases, protein kinase $\mathrm{C}$, and mitogen-activated protein kinases as well as transcription systems such as nuclear factor$\kappa \mathrm{B}(\mathrm{NF}-\kappa \mathrm{B})$ and $\mathrm{AP}-1 .^{35)}$ Moreover, these factors can be induced by inflammatory cytokines and reactive oxygen species. ${ }^{34)}$ Thus, one plausible explanation for the effects of $\mathrm{Cp}-\mathrm{Mn}$ and DiAc- $\mathrm{Cp}-\mathrm{Mn}$ is that these drugs suppress $i N O S$ mRNA expression via their inhibitory effect on KA-induced c-Fos and c-jun and $C O X-2$ expression probably in coordination with their intrinsic properties as an antioxidant. However, the same does not seem to be true of curcumin suppression of KA-induced $i N O S$ gene expression in the hippocampus, since this compound had no effect on other neurotoxic marker genes tested in this study. Curcumin reportedly suppresses the activation of NF- $\kappa \mathrm{B}$, one of the transcription factors of the $i N O S$ gene, in a cultured cell by inhibiting the nuclear translocation of $\mathrm{p} 65$ and degradation of $\mathrm{I} \kappa \mathrm{B}$; therefore, it is likely that the reduction of $i N O S$ mRNA expression by curcumin may be due to the suppression of NF- $\kappa \mathrm{B}$ activation. ${ }^{36)}$

\section{CONCLUSION}

Systemic injection of KA induced seizures and up-regulated various neurotoxic marker genes such as immediate early genes (c-Fos, c-jun, COX-2, BDNF and hsp70) and a delayed response gene $(i N O S)$ in the hippocampus after KA injection. Pretreatment with $\mathrm{Cp}-\mathrm{Mn}$ and $\mathrm{DiAc}-\mathrm{Cp}-\mathrm{Mn}$ delayed the onset but not severity of KA-induced seizures and decreased the expression of neurotoxic markers, and iNOS caused by KA, whereas curcumin attenuated only the $i N O S$ expression. It is, therefore, likely that the neuroprotective effects of $\mathrm{Cp}-\mathrm{Mn}$ and $\mathrm{DiAc}-\mathrm{Cp}-\mathrm{Mn}$ are due to the suppression of these potential markers of neuronal injury and may account for the findings that $\mathrm{Cp}-\mathrm{Mn}$ and DiAc-Cp-Mn showed a more potent neuroprotective effect than curcumin, their parent compound. These findings support the potential superiority of $\mathrm{Cp}-\mathrm{Mn}$ and $\mathrm{DiAc}-\mathrm{Cp}-\mathrm{Mn}$ in the treatment of excitotoxicity-induced neurodegenerative diseases.

Acknowledgements This work was supported by Grants-in-Aid for Leading Research Utilizing the Potential of Regional Science and Technology from the Ministry of Education, Culture, Sports, Science and Technology of Japan.

\section{REFERENCES}

1) Das K. C., Das C. K., Biochem. Biophys. Res. Commun., 295, 62-66 (2002).

2) Vajragupta O., Boonchoong P., Berliner L. J., Free Radic. Res., 38, 303-314 (2004).

3) Sumanont Y., Murakami Y., Tohda M., Vajragupta O., Matsumoto K., Watanabe H., Biol. Pharm. Bull., 27, 170-173 (2004).

4) Vajragupta O., Boonchoong P., Watanabe H., Tohda M., Kummasud N., Sumanont Y., Free Radic. Biol. Med., 35, 1632-1644 (2003).

5) Sperk G., Prog. Neurobiol., 42, 1-32 (1994).

6) Kashihara K., Sakai K., Marui K., Shohmori T., Neurosci. Res., 32, 189-194 (1998)

7) Coyle J. T., Puttfarcken P., Science, 262, 689-695 (1993).

8) Bondy S. C., Lee D. K., Brain Res., 610, 229-233 (1993).

9) Schulz J. B., Henshaw D. R., Siwek D., Jenkins B. G., Ferrante R. J., Cipolloni P. B., Kowall N. W., Rosen B. R., Beal M. F., J. Neurochem., 64, 2239-2247 (1995)

10) Sperk G., Lassmann H., Baran H., Kish S. J., Seitelberger F., Hornykiewicz O., Neuroscience, 10, 1301-1315 (1983).

11) Zagulska-Szymczak S., Filipkowski R. K., Kaczmarek L., Neurochem. Int., 38, 485-501 (2001).

12) Yoneda Y., Kuramoto N., Kitayama T., Hinoi E., Prog. Neurobiol., 63, $697-719$ (2001).

13) Herdegen T., Claret F. X., Kallunki T., Martin-Villallba A., Winter C. Hunter T., Karin M., J. Neurosci., 18, 5124-5135 (1998).

14) Kaminska B., Filipkowski R. K., Zurkowska G., Lason W., Przewlocki R., Kaczmarek L., Eur. J. Neurosci., 6, 1558-1566 (1994).

15) Ernfors P., Bengzon J., Kokaia Z., Persson H., Lindvall O., Neuron, 7, $165-176$ (1991)

16) Scharfman H. E., Goodman J. H., Sollas A. L., J. Neurosci., 19, 5619-5631 (1999)

17) Dugich-Djordjevic M. M., Tocco G., Lapchak P. A., Pasinetti G. M., Najm I., Baudry M., Hefti F., Neuroscience, 47, 303-315 (1992).

18) Sumanont Y., Murakami Y., Tohda M., Vajragupta O., Watanabe H., Matsumoto K., Life Sci., 78, 1884-1891 (2006).

19) Radwanska K., Caboche J., Kaczmarek L., Eur. J. Neurosci., 22, 939948 (2005).

20) Matsuoka Y., Okazaki M., Kitamura Y., Takata K., Tooyama I., Kimura H., Taniguchi T., Brain Res., 836, 213-217 (1999).

21) Lian X. Y., Zhang Z. Z., Stringer J. L., Epilepsia, 46, 15-22 (2005).

22) Lothman E. W., Collins R. C., Brain Res., 218, 299-318 (1981).

23) Velisek I., Mares P., Physiol. Res., 53, 453-461 (2004).

24) Binder D. K., Croll S. D., Gall C. M., Scharfman H. E., Trends Neurosci., 24, 47-53 (2001).

25) Croll S. D., Suri C., Compton D. L., Simmons M. V., Yancopoulos G. D., Lindsay R. M., Wiegand S. J., Rudge J. S., Scharfman H. E., Neuroscience, 93, 1491-1506 (1999).

26) Kokaia M., Ernfors P., Kokaia Z., Elmer E., Jaenisch R., Lindvall O., Exp. Neurol., 133, 215-224 (1995).

27) Binder D. K., Routbort M. J., Ryan T. E., Yancopoulos G. D., McNamara J. O., J. Neurosci., 19, $1424-1436$ (1999).

28) Gass P., Prior P., Kiessling M., Neuroscience, 65, 27-36 (1995).

29) Zhang X., Boulton A. A., Yu P. H., Eur. J. Neurosci., 8, 1432-1440 (1996).

30) Bossy-Wetzel E., Bakiri L., Yaniv M., EMBO J., 16, 1695-1709 (1997). 
31) Becker A. J., Gillardon F., Blumcke I., Langendorfer D., Beck H., Wiestler O. D., Brain Res. Mol. Brain Res., 67, 172-176 (1999).

32) Farooqui A. A., Ong W. Y., Lu X. R., Halliwell B., Horrocks L. A., Brain Res. Rev., 38, 61-78 (2001).

33) Kawaguchi K., Hickey R. W., Rose M. E., Zhu L., Chen J., Graham S. H., Brain Res., 1050, 130-137 (2005).
34) Surh Y. J., Chun K. S., Cha H. H., Han S. S., Keum Y. S., Park K. K., Lee S. S., Mutat. Res., 480-481, 243-268 (2001).

35) Jana M., Anderson J. A., Saha R. N., Liu X., Pahan K., Free Radic. Biol. Med., 38, 655-664 (2005).

36) Singh S., Aggarwal B. B., J. Biol. Chem., 270, 24995-25000 (1995). 